\title{
Prototheca zopfii isolated from bovine mastitis induced oxidative stress and apoptosis in bovine mammary epithelial cells
}

\author{
Muhammad Shahid ${ }^{1}$, Jian Gao ${ }^{1}$, Yanan Zhou ${ }^{1}$, Gang Liu ${ }^{1}$, Tariq Ali ${ }^{1}$, Youtian Deng $^{1}$, \\ Naveed Sabir ${ }^{1}$, Jingliang Su${ }^{1}$, Bo Han ${ }^{1}$ \\ ${ }^{1}$ College of Veterinary Medicine, China Agricultural University, Beijing 100193, P R China
}

Correspondence to: Bo Han, email: hanbo@cau.edu.cn

Keywords: bovine mastitis, Prototheca zopfii, bMECs, apoptosis, oxidative stress

Received: February 17, 2017 Accepted: March 19, 2017 Published: March 29, 2017

Copyright: Shahid et al. This is an open-access article distributed under the terms of the Creative Commons Attribution License (CC-BY), which permits unrestricted use, distribution, and reproduction in any medium, provided the original author and source are credited.

\section{ABSTRACT}

Bovine protothecal mastitis results in considerable economic losses worldwide. However, Prototheca zopfii induced morphological alterations and oxidative stress in bovine mammary epithelial cells (bMECs) is not comprehensively studied yet. Therefore, the aim of this current study was to investigate the $P$. zopfii induced pathomorphological changes, oxidative stress and apoptosis in bMECs. Oxidative stress was assessed by evaluating catalase (CAT), superoxide dismutase (SOD), glutathione peroxidase (GPX), malondialdehyde (MDA) contents and lactate dehydrogenase (LDH) activity, while ROS generation and apoptosis was measured by confocal laser scanning microscopy. The results revealed that infection of $\boldsymbol{P}$. zopfii genotype II (GTII) significantly changed bMECs morphology, increased apoptotic rate and MDA contents at $12 \mathrm{~h}(p<0.05)$ and 24 h $(p<0.01)$ in comparison with control group, in time-dependent manner. LDH activity and ROS generation was also increased $(p<0.01)$ at $12 \mathrm{~h}$ and $24 \mathrm{~h}$. However, SOD and CAT contents in bMECs infected with GTII were decreased $(p<0.05)$ at 12 h, while GPX $(p<0.01)$, SOD $(p<0.05)$ and CAT $(p<0.01)$ levels were reduced at 24 h. In case of GTI, only CAT and GPx activities were significantly decreased when the duration prolonged to $24 \mathrm{~h}$ but lesser than GTII. This suggested that GTII has more devastating pathogenic effects in bMECs, and the findings of this study concluded that GTII induced apoptosis and oxidative stress in bMECs via the imbalance of oxidant and antioxidant defenses as well as the production of intracellular ROS.

\section{INTRODUCTION}

Bovine mastitis is an inflammatory response of the udder, which is characterized by pathological alterations in mammary gland and physio-chemical changes in milk. Bovine protothecal mastitis is mostly caused by $P$. zopfii [1]. Prototheca is achlorophyllous unicellular algae, which is closely related to chlorella species [2]. The cell wall of these microalgae contains sporopollenin, a robust biopolymer which makes the organism highly resistant to enzymatic degradation, mechanical injuries, physical and chemical treatments [3].

To date, six Prototheca species have been reported: P. blaschkeae, P. cutis, P. stagnora, P. wickerhamii, $P$. ulmea, and P. zopfii $[2,4]$. P. zopfii, P. cutis, P. wickerhamii and $P$. blaschkeaeare are causative agents of the protothecal infection in animals and human beings [4-6]. There are different clinical manifestations of protothecosis in different host species. $P$. wickerhamii and $P$. zopfii can cause protothecosis in human beings, characterized by local cutaneous lesions, olecranon bursal infection and also disseminated infection [7].

P. zopfii genotype-II (GTII) is linked with the most severe forms of protothecosis in animals, like bovine mastitis or canine encephalitis. Whereas genotype-I (GTI) is reported to be non-pathogenic in cattle [8-10]. Protothecal mastitis in cattle is characterized by abrupt decrease in milk production and increase in somatic cell count, which may lead to culling of dairy cow [11]. It is becoming serious problem for dairy cattle throughout the world due to its inherent resistance against different antimicrobials [12]. Various predisposing factors can exacerbate protothecal mastitis, like poor dairy herd management and unhygienic status, as under suitable conditions it can multiply in the surrounding environments as saprophytic form [13]. 
In bovine mastitis, oxidative stress occurs due to infection of pathogen that triggers the immune response and induces the reactive oxygen species (ROS) generation in cells [14]. The proliferation and apoptosis of bovine mammary epithelial cells (bMECs) under oxidative stress are modulated by cellular antioxidant status [15]. Lipid peroxidation in cell is due to the oxidative degradation of lipid which results in cell damage. Malondialdehyde (MDA) is a common indicator to assess the extent of lipid peroxidation [16]. The antioxidant defense mechanism of mammalian cells has the ability to counteract the detrimental effects of free radicals induced lipid peroxidation. Antioxidant enzymes such as catalase (CAT), superoxide dismutase (SOD) and glutathione peroxidase (GPx) react synergistically with each other to detoxify the lethal effects of lipid peroxidation [17]. Oxidative stress could contribute to compromise immunity and increase the severity of disease outcome, and also take part in the pathogenesis of bovine mastitis $[18,19]$. The cytotoxic effect of oxidant is well known through protein, amino acid oxidation and DNA damage, as well as the ROS can take part in intracellular signals transmission. ROS reduces the antioxidant protection mechanisms and causes tissue damage in inflammatory process. Oxidative stress to bovine mammary secretary cells was proposed to decrease the secretary cells number and milk production [20]. In addition, lactate dehydrogenase (LDH) release assay could be used to evaluate cytopathic effect of pathogen [21]. LDH is normally present in the cytoplasm and release into the cell culture medium through damaged cell membrane. The bMECs are used as an alternative to in vivo study [22]. BMECs are less expensive and could be an ideal model to evaluate in vitro oxidative stress induced by $P$. zopfii, which may provide some comprehension in the pathogenesis of protothecal mastitis. Thus, in current study the activities of these enzymes were assessed to evaluate the oxidative stress in bMECs induced by P. zopfii.

The development of bovine protothecosis and the pathogenic diversity among the various Prototheca spp. and genotypes are scantily understood. Our earlier report was an attempt to study the immune response in bMECs challenged with $P$. zopfii remain inconclusive due to the fact that oxidative stress in bMECs induced by Prototheca infection was not investigated [23]. Therefore, the present study was conducted to investigate the effect of oxidant and antioxidant enzymes in bMECs after in vitro infection of GTI and GTII. Additionally, patho-morphological and apoptotic effects of both strains were also carried out by hematoxylin and eosin staining, and annexin V-FITC and PI staining, respectively.

\section{RESULTS}

\section{Prototheca zopfii induced apoptosis in bMECs}

To investigate the pathogenic effect of $P$. zopfii GTI and GTII on bMECs, the cultured bMECs were treated with $P$. zopfii GTI and GTII for $4 \mathrm{~h}, 12 \mathrm{~h}$ and $24 \mathrm{~h}$ using annexin V-FITC and PI staining. The apoptotic cells were significantly increased in case of $P$. zopfii GTII infected group both in early stage (annexin V-positive cells) and late stage (annexin V-and PI-double positive cells) on $12 \mathrm{~h}$ and $24 \mathrm{~h}$ (Figure 1A-1C). The number of apoptotic cells were increased from $20.16 \% \pm 5.02 \%(p<0.05)$ to $72.00 \% \pm$ $13.5 \%(p<0.01)$ with increase in time of infection from 12 $\mathrm{h}$ to $24 \mathrm{~h}$ (Figure 1D). However, the GTI could not induce significant apoptotic effect in bMECs as compared to control.

\section{Morphological alterations in infected bMECs}

The GTII infected bMECs exhibited discrete morphological changes evidenced by the loss of cellular limits and alterations in cell volume at $12 \mathrm{~h}$ and $24 \mathrm{~h}$ post-infection which showed the cytopathic effects of P. zopfii GTII (Figure 2F, 2I). While GTI depicted slight morphological changes at $24 \mathrm{~h}$ (Figure $2 \mathrm{H}$ ). importantly, adhesion of both $P$. zopfii genotypes to bMECs was seen at $4 \mathrm{~h}$ (Figure 2B, 2C), $12 \mathrm{~h}$ (Figure 2E, 2F) and $24 \mathrm{~h}$ (Figure 2H, 2I) post-infection. Control group cells did not show any apparent alterations in cell morphology (Figure 2A, 2D and $2 \mathrm{G})$.

\section{Oxidative stress indicators}

The results of antioxidant enzyme activities of GPx, SOD and CAT did not show any significant differences in both GTI and GTII treated and control group at $4 \mathrm{~h}$ post-infection (Figures 3, 4 and 5). At 12 hours, there was a significant decrease in the activities of CAT $(70.77 \pm 1.169, p<0.05)$ and $\operatorname{SOD}(4.98 \pm 0.62$, $p<0.05)$ in GTII treated group in comparison with control group, while GTI infected group could not show any significance differences in various enzymes levels. At 24 hours of infection, there was a significant lower activities of CAT (50.55 $\pm 6.48, p<0.01)$, SOD (3.402 \pm 0.57 , $p<0.05)$ and GPx $(1.073 \pm 0.13, p<0.01)$ were observed in GTII bMECs. However, in case of GTI infected group, there were a slightly significant differences in CAT $(77.07 \pm 10.92, p<0.05)$ and GPx $(1.35 \pm 0.038, p<0.05)$ only at $24 \mathrm{~h}$ as compared to control group.

In contrast, MDA content was significantly increased at $12 \mathrm{~h}(2.74 \pm 0.073, p<0.05)$ and $24 \mathrm{~h}(4.39$ $\pm 0.35, p<0.01)$ in GTII treated group compared with control group. While in case of GTI infection, there was significantly increased in MDA content only at $24 \mathrm{~h}(2.62$ $\pm 0.34, p<0.05)$ in comparison with control group, but the expression was lower than the GTII group as shown in Figure 6.

\section{P. zopfii triggered lactate dehydrogenase (LDH) release}

As shown in Figure 7, in case of GTII infection, there was significantly higher release of $\mathrm{LDH}$ activities 
at $12 \mathrm{~h}(0.876 \pm 0.0382)$ and $24 \mathrm{~h}(1.72 \pm 0.042)$ postinfection as compared with GTI infected and control groups. This indicated that GTII seriously damage the bMECs membranes with the passage of time. In case of GTI treated group, there was also significant increase $(p<0.05)$ of LDH level at $12 \mathrm{~h}(0.82 \pm 0.038)$ and $24 \mathrm{~h}$ $(1.106 \pm 0.042)$ as compared to control group; however, this effect was lesser than GTII.

\section{$P$. zopfii stimulated reactive oxygen species (ROS)}

ROS generation in bMECs after $P$. zopfii genotypes infection is shown in Figure 8 . The production of ROS after GTII infection was significantly increased $(50.29 \pm 6.158$ to $82.48 \pm 8.078, p<0.01)$ with the passage of time from $12 \mathrm{~h}$ to $24 \mathrm{~h}$ in comparison with GTI and control groups (Figure 8A, 8B). While in case of GTI infection, ROS production was increased only after $24 \mathrm{~h}$ of infection $(47.72 \pm 9.89, p<0.05)$. Our findings of the confocal laser microscopy were also in compliance with the results of flow cytometry analysis (Figure 9).

\section{DISCUSSION}

The mammary tissues during production have complex biochemical reactions and a vigorous metabolism. Bovine mastitis is associated with oxidative stress in which significant increase of reactive oxygen species (ROS), malondialdehyde (MDA) and nitric oxide (NO) and significant decrease of glutathione (GSH), that leads to inflammation and cell apoptosis [27, 28]. Therefore, the susceptibility of the mammary gland to immune dysfunction and inflammatory disorder decrease the health status of udder, milk production and quality of milk [29, 30]. P. zopfii GTII is a potential cause of bovine protothecal mastitis characterized as decrease in milk quantity and quality, and also associated with the abnormality of the effected quarters. Nevertheless, there is little published data about the pathogenesis of $P$. zopfii in bovine mastitis.

The present study was carried out to investigate the effect of $P$. zopfii on the oxidative stress indicators after in vitro infection of bMECs with $P$. zopfii GTI and GTII at $4 \mathrm{~h}, 12 \mathrm{~h}$ and $24 \mathrm{~h}$. The antioxidant enzymes such as GPx, CAT and SOD could be used to examine the condition of different antioxidant defense mechanisms against free radicals [31]. The present data elaborated that the enzyme contents of GPx, CAT and SOD were significantly lower in $P$. zopfii GTII treated groups compared with control group, which indicated $P$. zopfii GTII induces oxidative cell damage in a time-dependent manner. The GTI infection only at $24 \mathrm{~h}$ significantly altered the CAT and GPx activities but the effect was less prominent than

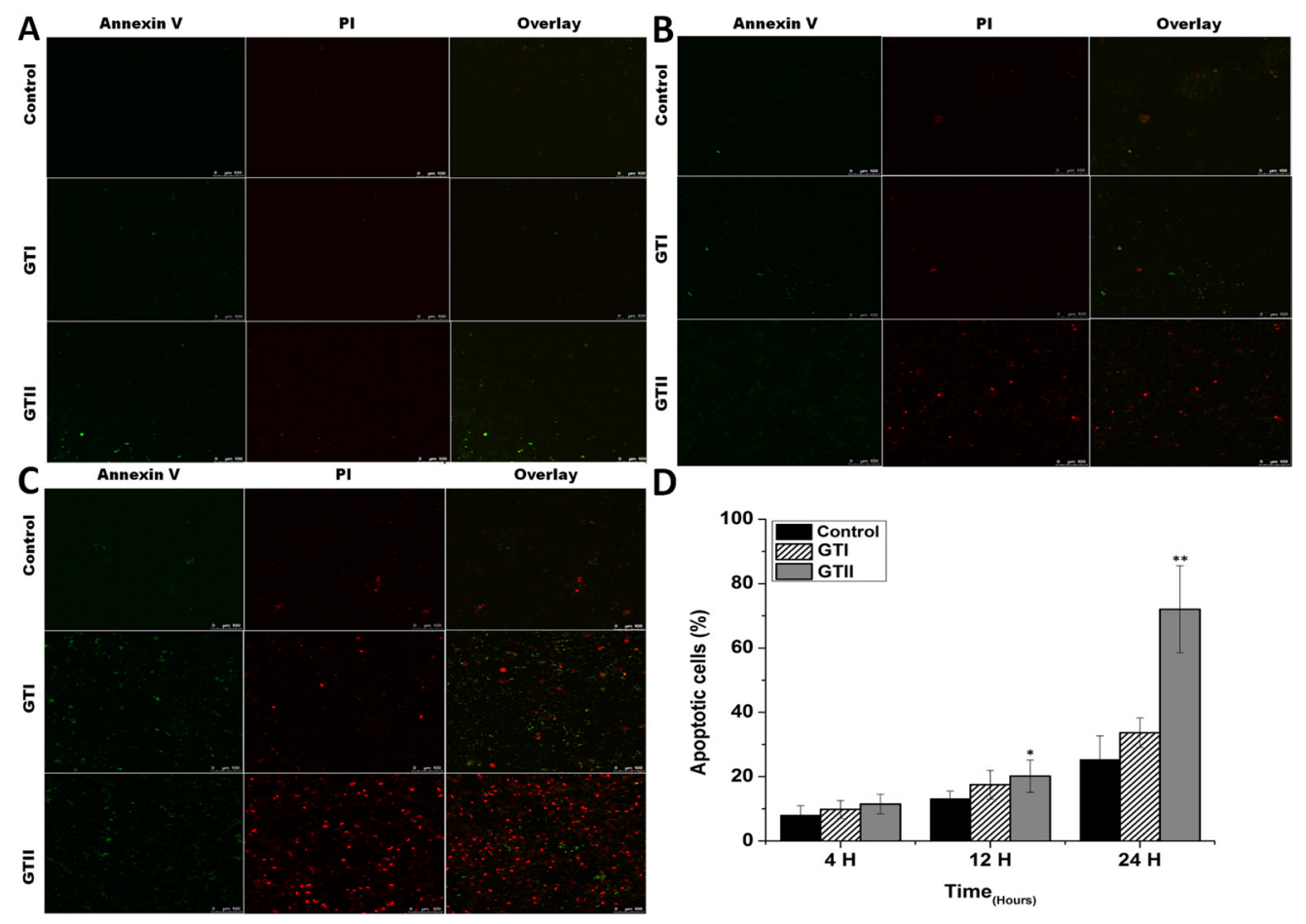

Figure 1: The bovine mammary epithelial cells stained with FITC-conjugated annexin-V (Green) and PI (Red) at $4 \mathrm{~h}$ (A), $12 \mathrm{~h} \mathrm{(B)} \mathrm{and} 24 \mathrm{~h}$ (C) after infection of $\boldsymbol{P}$. zopfii GTI and GTII. (A-C) The stained bMECs were observed by laser scanning confocal microscope, the upper panel represents normal cells, the middle panel shows representative bMECs treated with GTI, and the lower panel shows bMECs treated with GTII. (D) Shows the effects of $P$. zopfii GTI and GTII in bMECs apoptosis. ${ }^{*} p<0.05$ and $* * p<0.01$ indicate the significance and highly significance differences. 
GTII. This may be attributed to the longer duration of GT1 infection which might cause lethal effects in the bMECs. However, previous studies conducted in various countries declared that GTII is the causative organism of bovine mastitis and GT1 is never isolated from cases of mastitis. The antioxidant enzymes like SOD, CAT and GPx can eliminate a variety of active oxygen free radicals. The over-expression of antioxidant has the ability to block the activation of nuclear factor kappa-light-chainenhancer of activated B cells (NF- $\kappa \mathrm{B})$. Activated NF- $\kappa \mathrm{B}$ can also decrease SOD and increase MDA levels in cells under oxidative stress [32]. The enzyme activities of GPx, SOD, CAT, and the level of MDA are vital indicators of oxidative damage from free radicals and lipid peroxidation [33]. Cells contain a variety of antioxidants that play an important role in protection against high release of ROS in tissues during mammary gland infection [34]. This study is the first report about in vitro antioxidant activity induced by $p$. zopfii in bMECs.

Apoptotic activity plays a pivotal role in the development of bovine mastitis. In the present study we performed the PI and annexin-V FITC staining which elaborated that GTII significantly induced apoptosis in bMECs. Additionally, hematoxylin and eosin staining demonstrated that treatment with $P$. zopfii GTII for $12 \mathrm{~h}$ and $24 \mathrm{~h}$ causes prominent disruption of bMECs. We also examined the effect of $P$. zopfii-induced ROS production in bMECs. This showed that P. zopfii GTII induced a significant increase in ROS generation after $12 \mathrm{~h}$ and $24 \mathrm{~h}$ of infection in bMECs. These results are suggestive of $P$. zopfii GTII induced bMECs apoptosis and oxidative stress via the imbalance of oxidant and antioxidant defenses as well as the production of intracellular ROS. Malhotra et al. reported that persistent oxidative damage and ROS generation can stimulate the protein misfolding and initiate apoptotic cascade [35], which is in agreement with our observation. As the anti-oxidative potential of the cells diminished, this results in increase production of ROS which is lethal for the survival of cells.

The findings of previous studies confirmed that the P. zopfii GTII is the etiological agent of bovine protothecal mastitis $[8,9,26]$, this is in support of our study as in vitro infection of bMECs with GTII could significantly cause oxidative damages and apoptosis. However, in the current study the pathogenicity of $P$. zopfii was not confined to mammary gland, and immune responses to this pathogen in vivo may be much complex. This is needed to be further investigated by using in vivo model. The previous studies also confirmed the status of $P$. zopfii GTI as an environmental organism, without involvement in the pathology of mammary gland $[8,9,26]$. The severity and strength of the mammary gland immune response

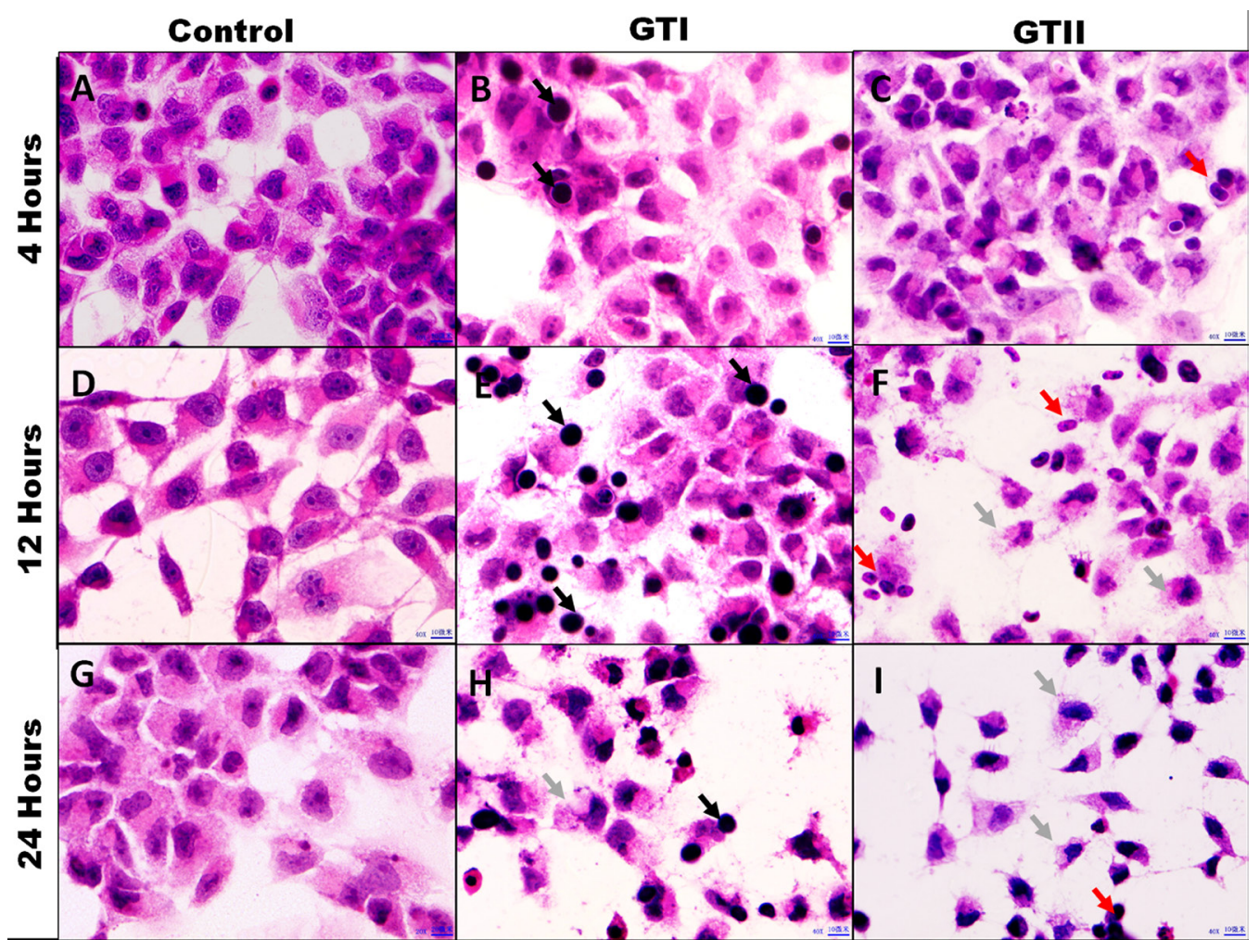

Figure 2: Morphological assessment of bMECs after infected with $\boldsymbol{P}$. zopfii GTI and GTII. Optical microscopy analysis. $(\mathbf{A}, \mathbf{D}, \mathbf{G})$ Control $4 \mathrm{~h}, 12 \mathrm{~h}$ and $24 \mathrm{~h}$; (B, E, H) P. zopfii GTI treatment for $4 \mathrm{~h}, 12 \mathrm{~h}$ and $24 \mathrm{~h}$; (C, F, I) P. zopfii GTII treatment for $4 \mathrm{~h}$, $12 \mathrm{~h}$ and $24 \mathrm{~h}$. Black arrow shows adhesion of $P$. zopfii GTI with cells. Red arrow indicates adhesion of $P$. zopfii GTII with cells. Gray arrow demonstrates the cells patho-morphological changes. 
depends on the type of pathogen and its virulence [1]. The studies about the recognition of potential virulence factors in $P$. zopfii GTII are currently in progress and a recent immunoproteomic investigation in this context revealed that genotype specific antigen/epitopes could be identified as potential virulence factors in case of $P$. zopfii GTII [36]. In contrast, GTI may be deficient in such virulence factor, which might clarify its nonpathogenic behavior.

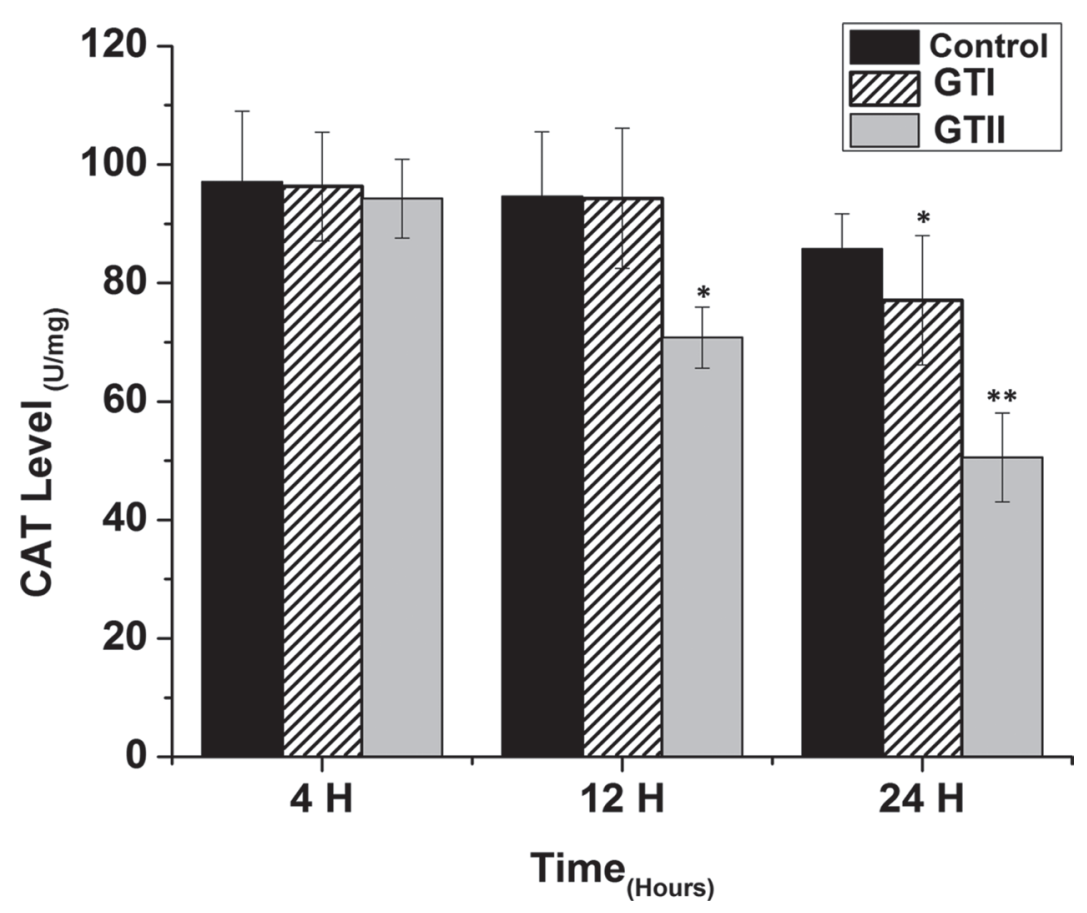

Figure 3: Effect of $\boldsymbol{P}$. zopfii GTI and GTII on catalase (CAT) content. The bMECs were challenged with GTI and GTII at 4 h, 12 h and $24 \mathrm{~h}$. Results indicated the means $\pm \mathrm{SD}$ of the three independent experiments. $* p<0.05, * * p<0.01$.

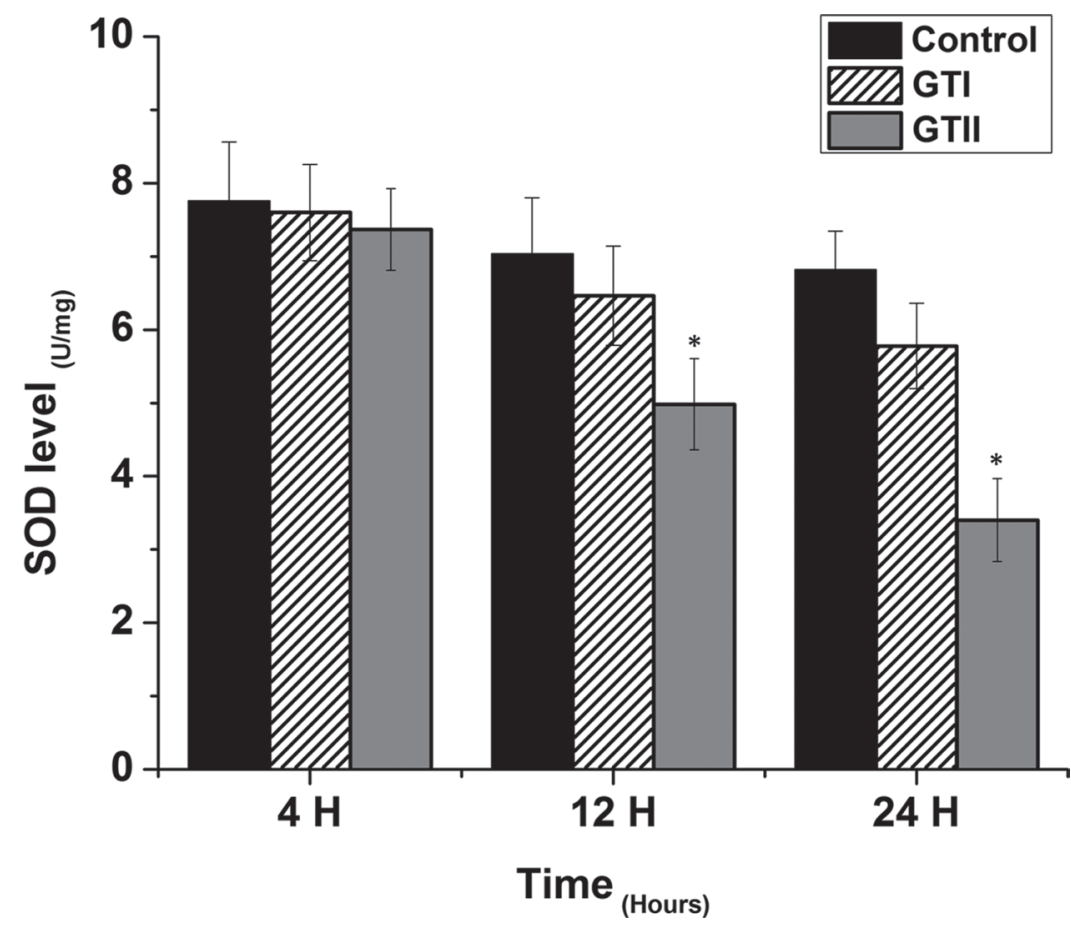

Figure 4: Effect of $\boldsymbol{P}$. zopfii GTI and GTII on superoxide dismutase (SOD) level. The bMECs were infected with GTI and GTII at $4 \mathrm{~h}, 12 \mathrm{~h}$ and $24 \mathrm{~h}$. Data represent the means $\pm \mathrm{SD}$ of the three independent experiments. ${ }^{*} p<0.05,{ }^{* *} p<0.01$. 
It is concluded that $P$. zopfii GTII induces oxidative damage and apoptosis. ROS generation and antioxidant activities in bMECs may play an important role in the pathogenesis of protothecal bovine mastitis. Further studies are needed to elaborate the specific mechanism involved in the oxidative stress induced by $P$. zopfii GTII.

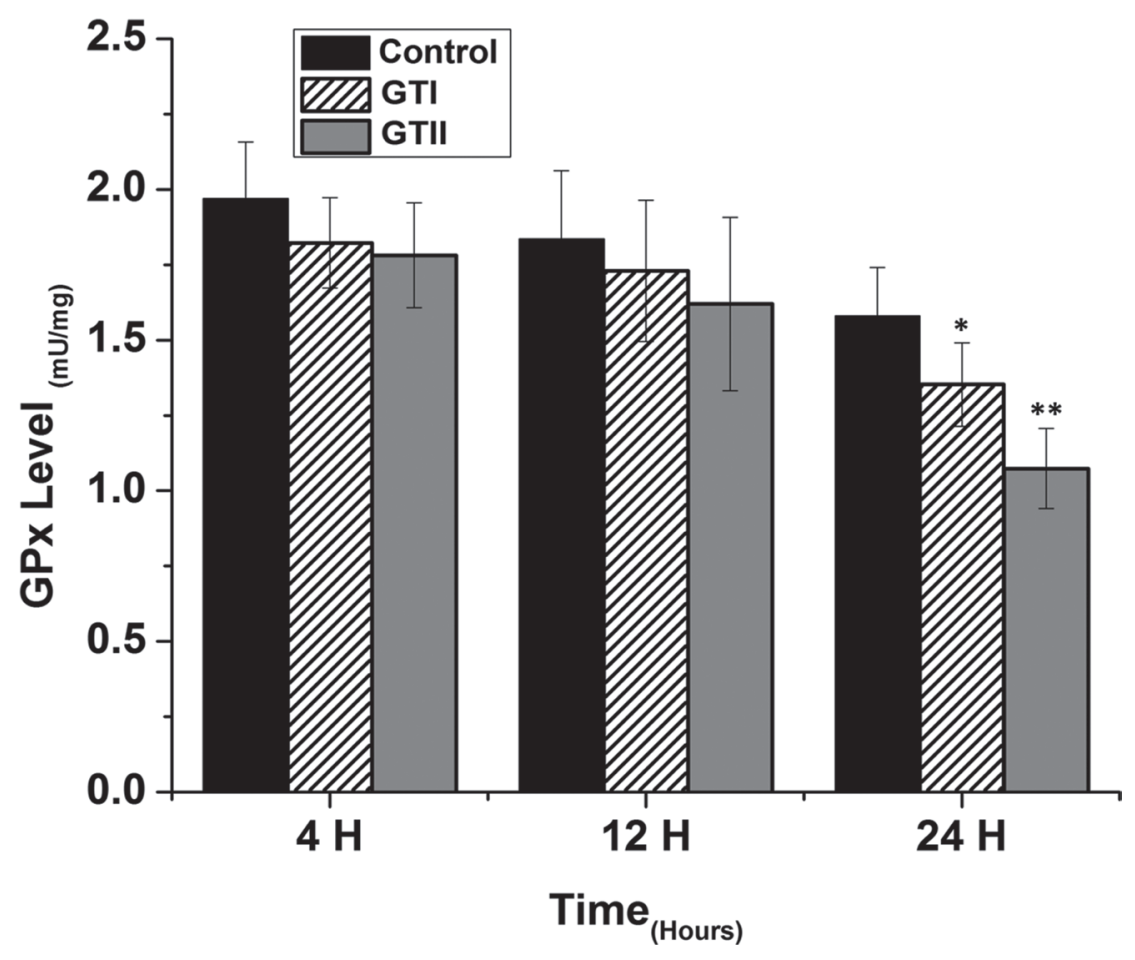

Figure 5: Effect of $\boldsymbol{P}$. zopfii GTI and GTII on glutathione peroxidase (GPx) activity. The bMECs were challenged with GTI and GTII at $4 \mathrm{~h}, 12 \mathrm{~h}$ and $24 \mathrm{~h}$. Results indicated the means $\pm \mathrm{SD}$ of the three independent experiments. $* p<0.05, * * p<0.01$.

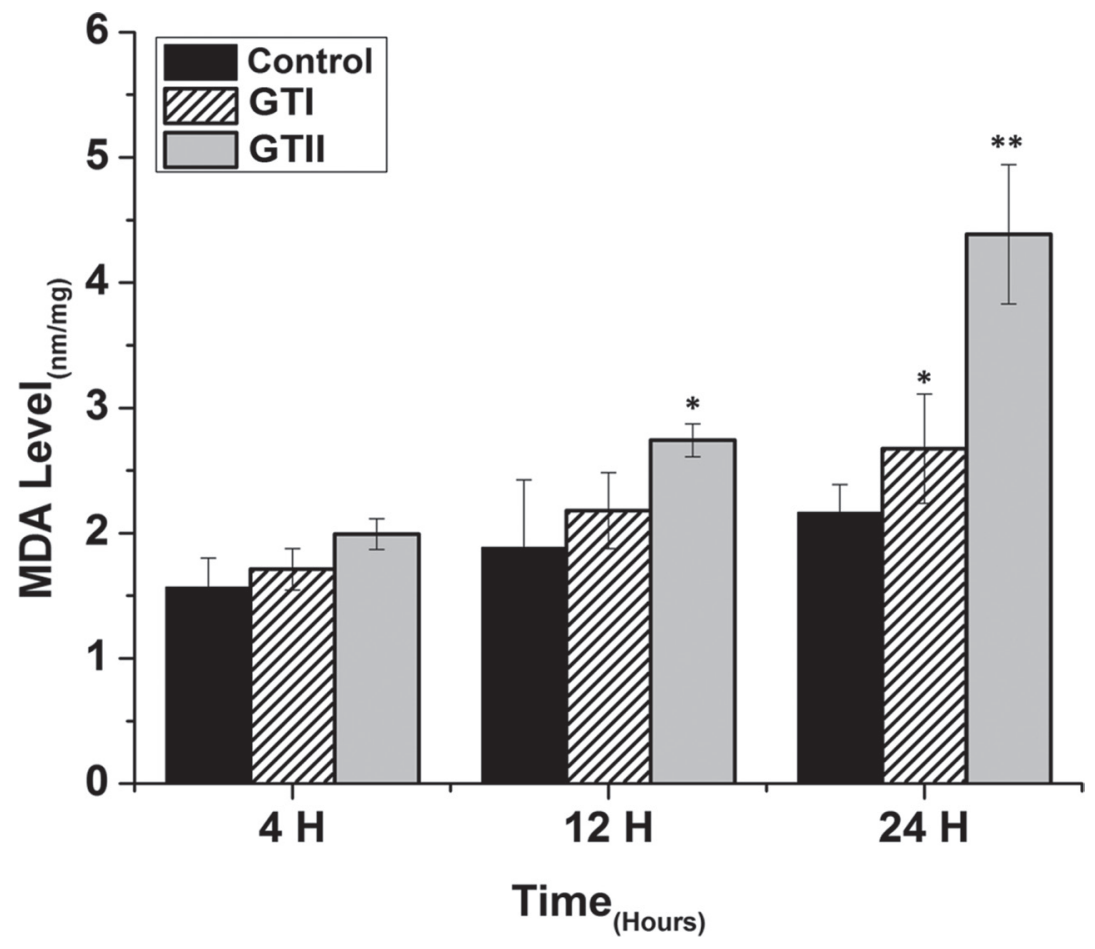

Figure 6: Effect of $\boldsymbol{P}$. zopfii GTI and GTII on intracellular malondialdehyde (MDA) concentration. The bMECs were infected with GTI and GTII at $4 \mathrm{~h}, 12 \mathrm{~h}$ and $24 \mathrm{~h}$. Data represent the means \pm SD of the three independent experiments. ${ }^{*} p<0.05,{ }^{* *} p<0.01$. 


\section{MATERIALS AND METHODS}

\section{Protothecal strains used in the study}

In the current study previously isolated strains of P. zopfii from dairy farms in Beijing were used, which were stored in our laboratory at College of Veterinary Medicine, China Agriculture University, Beijing [24-26]. The isolates were activated from stored stock by streaking on sabouraud dextrose agar (SDA, Difco ${ }^{\mathrm{TM}}$, Becton Dickison, Sparks, MD USA) and incubated at $37^{\circ} \mathrm{C}$ for $48 \mathrm{~h}$, then cultivated a single colony in sabouraud dextrose broth (SDB, Difco ${ }^{\mathrm{TM}}$, Becton Dickison, Sparks, MD USA) and incubated for 48 h. P. zopfii GTI and GTII were characterized by genotype specific primers [4]. Randomly selected three strains of each genotype (GTI and GTII) were used in following experiments, which were performed independently in triplicate.

\section{Cell culture}

Bovine mammary epithelial cells (bMECs) lines MAC-T (Shanghai Jingma Biological Technology Co., Ltd. China) were used in this study and maintained as described in our previous study [23]. The bMECs were cultured in DME/F 12 (HyClone, USA) medium along with Gibco ${ }^{\circledR}$ $10 \%$ fetal bovine serum (FBS; HyClone, USA), penicillin $(100 \mathrm{U} / \mathrm{mL}$; HyClone, USA) and streptomycin $(100 \mathrm{U} / \mathrm{mL}$; HyClone, USA) in cell culture plates (Corning, NY, USA).

\section{Infection of bMECs with $P$. zopfii genotypes}

The bMECs were infected with $P$. zopfii GTI and GTII for $4 \mathrm{~h}, 12 \mathrm{~h}$ and $24 \mathrm{~h}$; this was based on our previous work on cell viability and flow cytometry after protothecal infection for different time intervals (data not shown). BMECs were seeded on coverslips and incubated in 5\% $\mathrm{CO}_{2}$ at $37^{\circ} \mathrm{C}$. The logarithmic phase of GTI and GTII $\left(5.0 \times 10^{5}\right.$ cells/well $)$ were used in six-well plates.

\section{Annexin V-FITC and PI Staining}

Apoptosis induced by $P$. zopfii in bMECs was interpreted by annexin V-FITC and PI staining method. The bMECs $\left(1 \times 10^{5}\right.$ cells $\left./ \mathrm{mL}\right)$ were cultured as mentioned above. These cells were infected with GTI and GTII for $4 \mathrm{~h}, 12 \mathrm{~h}$ and $24 \mathrm{~h}$. After treatment, the coverslips were washed thrice with ice cold PBS and stained with FITC conjugated annexin- $\mathrm{V}$ mixture at room temperature (30 $\mathrm{min})$, then bMECs were stained with PI (5 min) after twice washing with cold ice PBS, finally, stained bMECs were analyzed under confocal laser-scanning microscope (LEICA TCS SP5-Germany) with an excitation/emission 488/ $525 \mathrm{~nm}$ for FITC and excitation/emission 488/620 nm for PI. The proportion of the positive apoptotic bMECs were expressed as percentage of counted cells.

\section{Optical microscopy}

The bMECs $\left(1 \times 10^{5}\right.$ cells $\left./ \mathrm{mL}\right)$ were seeded on glass coverslips as described above. The cells were infected with GTI and GTII $\left(5 \times 10^{5} \mathrm{CFU} / \mathrm{mL}\right)$ for $4 \mathrm{~h}, 12 \mathrm{~h}$ and $24 \mathrm{~h}$. The cells on coverslips were immediately fixed in absolute ethanol and then processed with $90 \%$ and $70 \%$ alcohol followed by hematoxylin staining. Then cells were washed with tap water and treated with $70 \%$ alcohol for decolorization. After ammonia water treatment cells were counter stained with eosin. Finally, the cover slip was

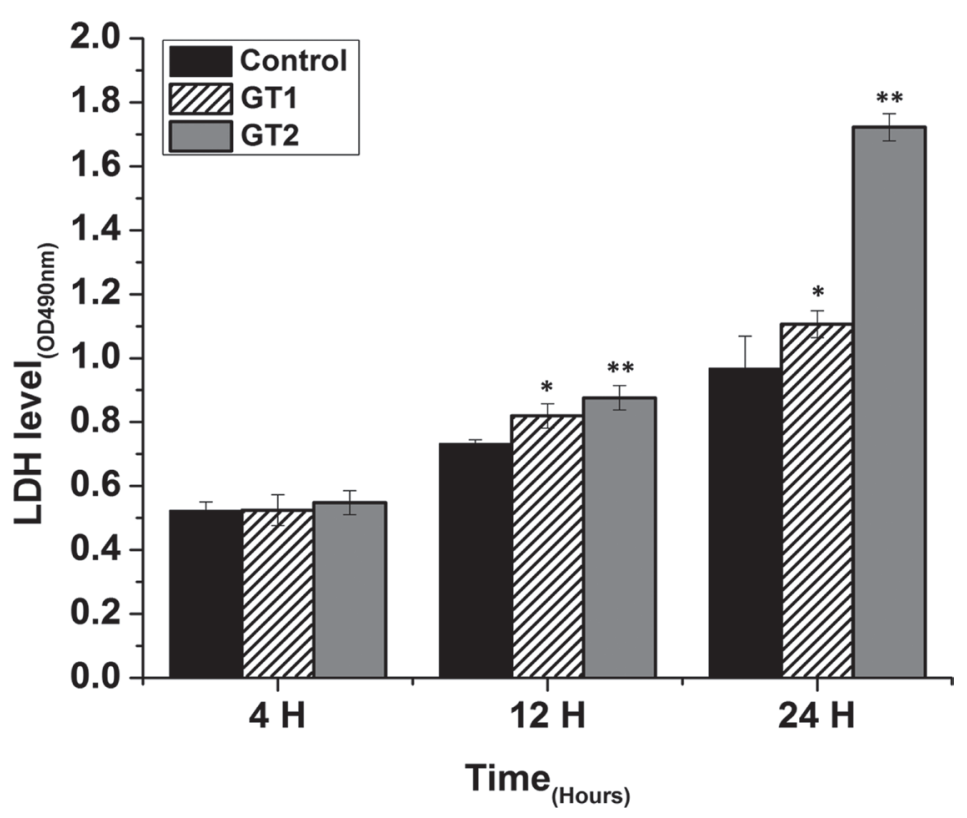

Figure 7: Effect of $\boldsymbol{P}$. zopfii GTI and GTII on LDH activity in the medium of cultured bovine mammary epithelial cells. Data indicated as mean $\pm \mathrm{SD}$ of three independent experiments. $* p<0.05, * * p 0.01$. 
dipped in 95\% alcohol and xylene for $30 \mathrm{sec}$. The cells were observed under an optical microscope (Olympus, Japan).

\section{Oxidative stress indicators analysis}

The concentrations of antioxidant enzyme like catalase (CAT; U/mg), superoxide dismutase (SOD; U/ $\mathrm{mg}$ ), glutathione peroxidase (GPx; $\mathrm{mU} / \mathrm{mg}$ ) and oxidant enzyme like malondialdehyde (MDA; $\mathrm{nmol} / \mathrm{mg}$ ) in bMECs were detected using a colorimetric method, according to the manufacturer's instructions (Nanjing Jiancheng Bioengineering Institute, Nanjing, China). The readings were recorded by the STAT FAX 2100 automatic enzyme standard instrument (Awareness Technology, Inc. USA).

\section{Lactate dehydrogenase activity (LDH) assay}

Lactate dehydrogenase (LDH) assay was used to assess the cytotoxic effect of GTI and GTII on bMECs.
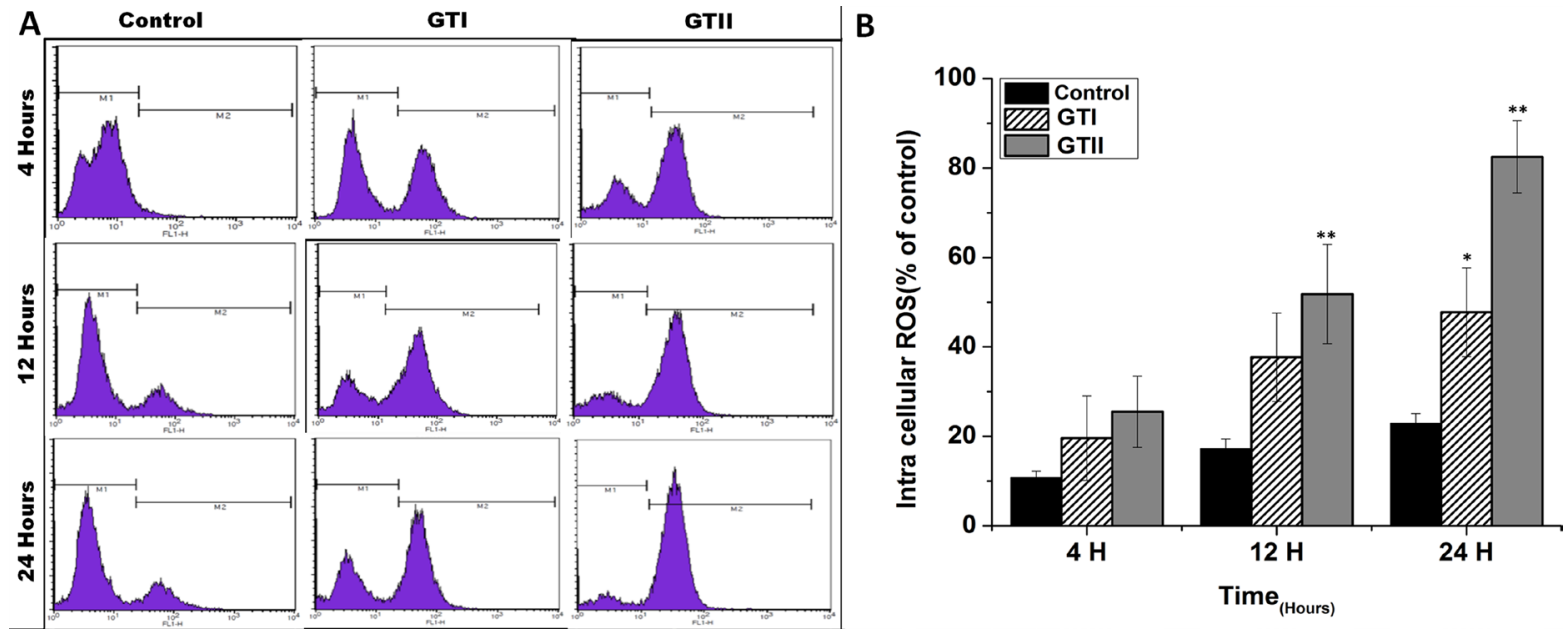

Figure 8: Comparison of ROS production in bMECs after infection of GTI and GTII by flow cytometry at 4 h, 12 h and $24 \mathbf{h}$. Results showed the means $\pm \mathrm{SD}$ of the three independent experiments. ${ }^{*} p<0.05,{ }^{*} p<0.01$.

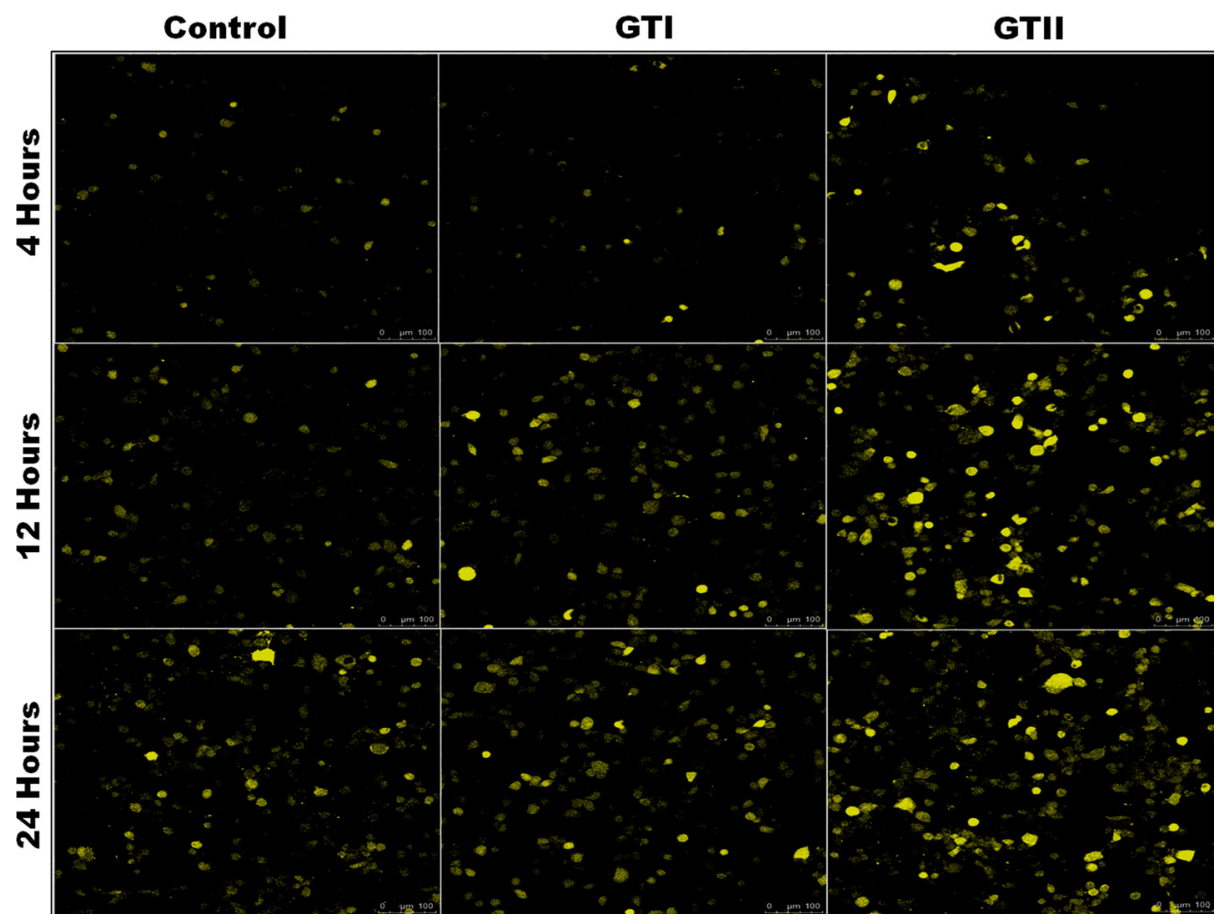

Figure 9: Effects of $\boldsymbol{P}$. zopfii GTI and GTII on ROS production. The bMECs challenged with GTI and GTII induced ROS production on time-dependent manner. ROS generation was observed using laser scanning confocal microscope. 
The bMECs $\left(1 \times 10^{5}\right.$ cells $\left./ \mathrm{mL}\right)$ were exposed to GTI and GTII at $4 \mathrm{~h}, 12 \mathrm{~h}$ and $24 \mathrm{~h}$. The supernatants were collected after incubation, and LDH assay kit (Dojingdo Laboratories, Kumamoto, Japan) was used to estimate the LDH level by biochemistry analyzer.

\section{Assessment of reactive oxygen species (ROS)}

The intracellular reactive oxygen species (ROS) in bMECs was evaluated using probe 2', $7^{\prime}$-dichlorofluorescein diacetate (DCFH-DA). The bMECs $\left(1 \times 10^{5}\right.$ cells $\left./ \mathrm{mL}\right)$ were treated with GTI and GTII $\left(5 \times 10^{5}\right.$ cells $\left./ \mathrm{mL}\right)$ for $4 \mathrm{~h}, 12 \mathrm{~h}$ and $24 \mathrm{~h}$. Infected cells were washed with PBS and treated with DCFH-DA ( $5 \mu \mathrm{mol} / \mathrm{L})(20 \mathrm{~min})$. After discarding the supernatant the treated cells were resuspended in PBS (two times). Fluorescence assays were measured and quantified by confocal laser-scanning microscope (LEICA TCS SP5Germany) using excitation/emission 525/610 $\mathrm{nm}$ and also analyzed by flow cytometry (Beckman, Fullerton, California, USA) at excitation/emission 488/525 nm.

\section{Statistical analysis}

The data were shown as mean value \pm SD of the three independent experiments. The data were statistically evaluated by the one-way analysis of variance (ANOVA) followed by least significant difference (LSD) test for multiple comparisons, and post hoc test using SPSS 19.0 (SPSS, Inc., Chicago, IL, USA). Moreover, $p<0.05$ and $p<0.01$ represent the significance and highly significance differences.

\section{ACKNOWLEDGMENTS AND FUNDING}

This research was supported by the National Natural Science Foundation of China (No. 31572587 and No. 3151101034). We thank Qing Zhang in Beijing University of Agriculture for technical support (confocal laserscanning microscope).

\section{CONFLICTS OF INTEREST}

The author declares that there is no conflicts of interest regarding the publication of this paper.

\section{REFERENCES}

1. Sharma N, Singh NK, Bhadwal MS. Relationship of somatic cell count and mastitis: an overview. Asian-Aust J Anim Sci. 2011; 24:429-438.

2. Satoh K, Ooe K, Nagayama H, Makimura K. Prototheca cutis sp. nov., a newly discovered pathogen of protothecosis isolated from inflamed human skin. Int $\mathrm{J}$ Syst Evol Microbiol. 2010; 60:1236-1240.
3. Ueno R. Visualization of sporopollenin-containing pathogenic green micro-alga Prototheca wickerhamii by fluorescent in situ hybridization (FISH). Can J Microbiol. 2009; 55:465-472.

4. Roesler U, Möller A, Hensel A, Baumann D, Truyen U. Diversity within the current algal species Prototheca zopfii: a proposal for two Prototheca zopfii genotypes and description of a novel species, Prototheca blaschkeae sp. nov. Int J Syst Evol Microbiol. 2006; 56:1419-1425.

5. Thompson G, Silva E, Marques S, Müller A, Carvalheira J. Algaemia in a dairy cow by Prototheca blaschkeae. Med Mycol. 2009; 47:527-531.

6. Camboim EK, Garino FJ, Dantas AF, Simoes SV, Melo MA, Azevedo EO, Mota RA, Riet-Correa F. Protothecosis by Prototheca wickerhamii in goats. Mycoses. 2011; 54:e196-200.

7. Lass-Florl C, Mayr A. Human protothecosis. Clin Microbiol Rev. 2007; 20:230-242.

8. Möller A, Truyen U, Roesler U. Prototheca zopfii genotype 2-The causative agent of bovine protothecal mastitis? Vet Microbiol. 2007; 120:370-374.

9. Osumi T, Kishimoto Y, Kano R, Maruyama H, Onozaki M, Makimura K, Ito T, Matsubara K, Hasegawa A. Prototheca zopfii genotypes isolated from cow barns and bovine mastitis in Japan. Vet Microbiol. 2008; 131:419-423.

10. Kishimoto $\mathrm{Y}$, Kano R, Maruyama H, Onozaki M, Makimura K, Ito T, Matsubara K, Hasegawa A, Kamata H. 26S rDNA-based phylogenetic investigation of Japanese cattle associated Prototheca zopfii isolates. J Vet Med Sci. 2010; 72:123-126.

11. Wawron W, Bochniarz M, Piech T, Wysocki J, Kocik M. Antimicrobial susceptibility of Prototheca zopfii isolated from bovine mastitis. Bull Vet Inst Pulawy. 2013; 57:485-488.

12. Capra E, Cremonesi P, Cortimiglia C, Bignoli G, Ricchi M, Moroni P, Pesce A, Luini M, Castiglioni B. Simultaneous identification by multiplex PCR of major Prototheca spp. isolated from bovine and buffalo intramammary infection and bulk tank. Lett Appl Microbiol. 2014; 59:642-647.

13. Costa EO, Carciofi AC, Melville PA, Prada MS, Schalch U. Prototheca sp. outbreak of bovine mastitis. Zentrablatt Für Veterinärmedizin (reihe B). 1996; 43:321-324.

14. Deng SL, Yu K, Jiang WQ, Li Y, Wang ST, Deng Z, Yao YC, Zhang BL, Liu GS, Liu YX, Lian ZX. Over-expression of Toll-like receptor 2 up-regulates heme oxygenase-1 expression and decreases oxidative injury in dairy goats. J Anim Sci Biotechnol. 2017; 8:3.

15. Miranda SG, Purdie NG, Osborne VR, Coomber BL, Cant JP. Selenomethionine increases proliferation and reduces apoptosis in bovine mammary epithelial cells under oxidative stress. J Dairy Sci. 2011; 94:165-173.

16. Li H, Song F, Duan LR, Sheng JJ, Xie YH, Yang Q, Chen Y, Dong QQ, Zhang BL, Wang SW. Paeonol and danshensu combination attenuates apoptosis in myocardial infarcted rats by inhibiting oxidative stress: Roles of Nrf2/HO-1 and PI3K/Akt pathway. Sci Rep. 2016; 6:1-14. 
17. Malathi M, Vijay M, Shivashankara AR. The role of oxidative stress and the effect of radiotherapy on the plasma oxidant-antioxidant status in head and neck cancer. J Clin Diagn Res. 2011; 5:249-51.

18. Aitken SL, Karcher EL, Rezamand P, Gandy JC, VandeHaar MJ, Capuco AV, Sordillo LM. Evaluation of antioxidant and proinflammatory gene expression in bovine mammary tissue during the periparturient period. J Dairy Sci. 2009; 92:589-598.

19. Sordillo LM, Aitken S. Impact of oxidative stress on the health and immune function of dairy cattle. Vet Immunol Immunopathol. 2009; 128:104-109.

20. Hadsell D, George J, Torres D. The declining phase of lactation: Peripheral or central, programmed or pathological? J Mammary Gland Biol Neoplasia. 2007; 12:59-70.

21. Viguier C, Arora S, Gilmartin N, Welbeck K, and O'kennedy R. Mastitis detection. current trends and future perspectives. Trend Biotechnol. 2009; 27:486-493.

22. Zhang L, Sun L, Wei R, Gao Q, He T, Xu C, Liu X, Wang R. Intracellular Staphylococcus aureus Control by Virulent Bacteriophages within MAC-T Bovine Mammary Epithelial Cells. Antimicrob Agents Chemother. 2017; 2: 61.

23. Deng ZJ, Shahid M, Zhang LM, Gao J, Gu XL, Zhang SY, Zou JQ, Fanning S, Han B. An investigation of the innate immune response in bovine mammary epithelial cells challenged by Prototheca zopfii. Mycopathologia. 2016; 181:823-832.

24. Gao J, Zhang HQ, He JZ, He YH, Li SM, Hou RG, Wu QX, Gao Y, Han B. Characterization of Prototheca zopfii associated with outbreak of bovine clinical mastitis in herd of Beijing, China. Mycopathologia. 2012; 173:275-281.

25. Chang R, Yang Q, Liu G, Liu Y, Zheng B, Su J, Han B. Treatment with gentamicin on a murine model of Protothecal mastitis. Mycopathologia. 2013; 175:241-248.

26. Shahid M, Ali T, Zhang LM, Hou RG, Zhang SY, Ding LD, Han DD, Deng ZJ, Rahman A, Han B. Characterization of Prototheca zopfi genotypes isolated from cases of bovine mastitis and cow barns in China. Mycopathologia. 2016; 181:185-195.
27. Sadek K, Saleh E, Ayoub M. Selective, reliable blood and milk bio-markers for diagnosing clinical and subclinical bovine mastitis. Trop Anim Health Prod. 2017; 49:431-437.

28. Barcelos RP, Royes LF, Gonzalez-Gallego J, Bresciani G. Oxidative stress and inflammation: liver responses and adaptations to acute and regular exercise. Free Radic Res. 2017; 6:1-32.

29. Rainard P, Cunha P, Bougarn S, Fromageau A, Rossignol C, Gilbert FB, Berthon P. T helper 17-associated cytokines are produced during antigen-specific inflammation in the mammary gland. PLoS One. 2013; 8:e63471.

30. Thompson-Crispi K, Atalla H, Miglior F, Mallard BA. Bovine mastitis: frontiers in immunogenetics. Front Immunol. 2014; 5: 493.

31. Shi H, Guo Y, Liu Y, Shi B, Guo X, Jin L, Yan S. The in vitro effect of lipopolysaccharide on proliferation, inflammatory factors and antioxidant enzyme activity in bovine mammary epithelial cells. Anim Nutrit. 2016; 2:99-104.

32. Zheng L, Xu Y, Lu J, Liu M, Bin Dai, Miao J, Yin Y. Variant innate immune responses of mammary epithelial cells to challenge by Staphylococcus aureus, Escherichia coli and the regulating effect of taurine on these bioprocesses. Free Radic Biol Med. 2016; 96:166-180.

33. Khodir AE, Ghoneim HA, Rahim MA, Suddek GM. Montelukast attenuates lipopolysaccharide-induced cardiac injury in rats. Hum Exp Toxicol. 2016; 35:388-397.

34. Jhambh R, Dimri U, Gupta VK, Rathore R. Blood antioxidant profile and lipid peroxides in dairy cows with clinical mastitis. Veterinary World. 2013; 6:271-273.

35. Malhotra JD, Kaufman RJ. Endoplasmic reticulum stress and oxidative stress: a vicious cycle or a double-edged sword? Antioxid Redox Sign. 2007; 9:2277-2294.

36. Irrgang A, Murugaiyan J, Weise C, Azab W, Roesler U. Well-known surface and extracellular antigens of pathogenic microorganisms among the immunodominant proteins of the infectious microalgae Prototheca zopfii. Front Cell Infect Microbiol. 2015; 5:67. 